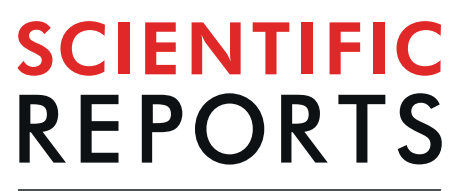

natureresearch

\title{
OPEN Physicochemical properties, microstructures, nutritional components, and free amino acids of Pleurotus eryngii as affected by different drying methods
}

\begin{abstract}
Rui-Lin Yang ${ }^{1}$, Qin $\mathrm{Li}^{2}$ \& Qing-Ping $\mathrm{Hu}^{2 *}$
In this study, we determined the influences of different drying techniques such as natural air (ND), hot-air (HD), vacuum (VD), infrared (ID), microwave (MD), and freeze drying (FD) methods on the color, shrinkage ratio (SR), rehydration ratio (RR), firmness, crispness, microstructures, nutritional components, and free amino acids of Pleurotus eryngii. The results showed that these parameters were markedly influenced by different drying techniques. Among them, FD was the most effective drying method which retained the main characteristics of the fresh $P$. eryngii in above mentioned indexes, followed by ND and $\mathrm{HD}$ at $40^{\circ} \mathrm{C}$. Finally, despite the least drying time, MD treatment was not suitable to the drying process of $P$. eryngii slices since it damaged physicochemical properties and caused massive losses of the main nutrients and free amino acids. The results will provide a theoretical basis for industrial processing of $P$. eryngii.
\end{abstract}

Pleurotus eryngii, often referred to as the king oyster mushroom, is called Xingbaogu in China. It is one of the important species of edible mushrooms commonly and has been widely cultivated and consumed in China because of its delicious taste, remarkable nutritional values and biological activities including antioxidant, antitumor, immunostimulatory activities, and modulating human gut microbiome ${ }^{1-3}$. The P. eryngii can be widely cultivated in lots of agricultural and industrial wastes conveniently and cheaply ${ }^{4}$. The production of the cultivated $P$. eryngii increased substantially at a rate of about $3 \times 10^{8} \mathrm{~kg} / \mathrm{year}$ in $\mathrm{Asia}^{5}$. Fresh P. eryngii slices can be cooked and retained its own firm textures ${ }^{1}$, and also can be fabricated into canned foods. Nevertheless, fresh P. eryngii is also one of the most perishable food raw materials and readily loses the best edible quality immediately after harvest because of its high in respiration rate, moisture content and nutrients, all of which made it easy to lose water or be attacked by microbes. Its shelf-life only reached about 3 weeks under the appropriate conditions $s^{6,7}$. Therefore, an effective preservation method was required for the industrial production and application of $P$. eryngii to extend its shelf-life.

Drying is a widely used and comparatively cheaper method for shelf-life extension of highly perishable mushrooms as it limited microbial growth, inhibited enzyme activity, and slowed down many moisture mediated reactions $^{8-10}$. In addition, dried $P$. eryngii can be also accepted by consumers with a similar high scores like fresh $P$. eryngii in all acceptability attributes (color, taste, and so on) and a strong purchase decision ${ }^{11}$. Drying methods are mainly composed of ND, HD, VD, fluidized bed drying, ID, MD, and FD based on different drying mechanisms ${ }^{12,13}$. For the reason that drying is a complex process involving continuous heat and mass transfer, it may accompany with significant changes in the nutrients, phytochemicals compositions, surface morphology and internal structure as well as physical properties of the products ${ }^{8,9,14-16}$, and even influence in vitro digestibility of substances ${ }^{17}$. For dried agricultural products, color is one of the most important quality indexes that influenced consumer appetite, acceptance and commodity value of products. The physical characteristics such as firmness, crispness, shrinking, and dehydration capacity are usually used to evaluate the mechanical properties and are defined as the resistance of a material to deformation or penetration, and are influenced by surface and internal 


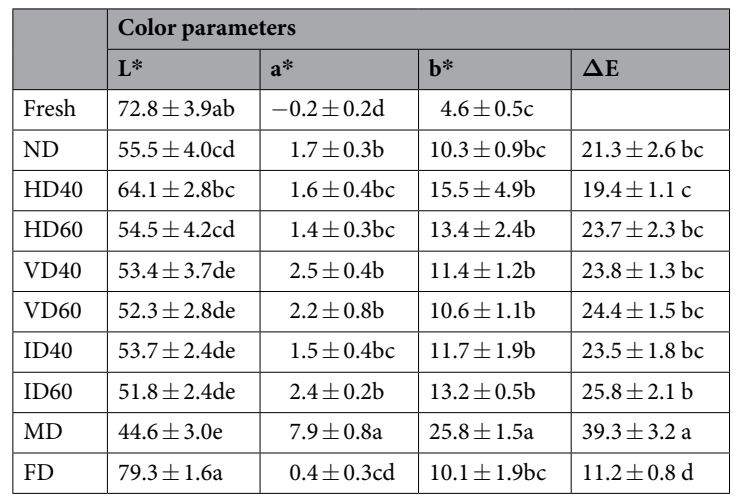

Table 1. Color of fresh and dried P. eryngii slices. Values are expressed as mean $\pm \mathrm{SD}$ of triplicate measurements. Different letters within a column indicate statistically significant differences between the means $(\mathrm{p}<0.05)$ for $\mathrm{L}^{*}, \mathrm{a}^{*}, \mathrm{~b}^{*}$ and $\Delta \mathrm{E}$.

structure. Most importantly, these parameters can affect the packaging, transportation and edible quality of dried products. In addition, free amino acids are important taste active compounds in edible fungi, especially Asp and Glu, which are responsible for umami flavour of edible fungi ${ }^{9}$. Therefore, the choice of the drying methods and processing parameters is of great importance for Pleurotus eryngii. Chen et al. only optimized the technology parameters of Pleurotus eryngii by microwave-vacuum drying based on quality and energy consumption ${ }^{18}$. Su et al. investigated drying characteristics and water dynamics during microwave hot-air flow rolling drying of Pleurotus eryngi $i^{19}$. Li et al. mainly studied the effects of different drying methods on the tasty compounds but did not investigate the changes in color, physical and texture properties of dried $P$. eryngii ${ }^{20}$. Therefore, these studies are still inadequate on the choice of drying methods, drying temperatures as well as research content and parameters for drying processing of $P$. eryngii, which can not be fully and objectively reflected the effect of different drying methods on sensory, physical and chemical qualities of dried P. eryngii.

The purpose of this study is to assess the influences of different drying methods and temperatures on the physicochemical properties, microstructures, nutritional compositions, and free amino acids of $P$. eryngii, and recommend a desirable drying method. These will provide valuable information to maximally retain the original nutrients and sensory qualities of $P$. eryngii during drying process.

\section{Results and Discussion}

Color determination. Generally speaking, the smaller the total color difference $(\Delta \mathrm{E})$, the closer the color to the fresh sample. The color values of fresh and dried P. eryngii slices dried with different methods are shown in Table 1. Except FD, all dried samples exhibited lower lightness ( $\mathrm{L}^{*}$ value), higher redness ( $\mathrm{a}^{*}$ value) and yellowness $\left(b^{*}\right.$ value) compared with fresh $P$. eryngii, and a significant difference $(p<0.05)$ was found in $L^{*}, a^{*}$, and $b^{*}$ values among different drying methods. Similar results were also reported in shiitake mushrooms $s^{9,21,22}$. As expected, the $\mathrm{L}^{*}$ values closest to the fresh sample and lowest $\Delta \mathrm{E}$ values were found in FD samples (Table 1), indicating that the color parameters of FD were close to those of fresh sample. This can be explained by the fact that less oxygen was present in a drying chamber under low temperature and pressure, which led to less intense enzymatic browning reactions and non-enzymatic browning reactions. HD sample at $40^{\circ} \mathrm{C}(\mathrm{HD} 40)$ possessed higher $\mathrm{L}^{*}$ and lower $\Delta \mathrm{E}$ values compared with $\mathrm{HD}$ at $60^{\circ} \mathrm{C}(\mathrm{HD} 60), \mathrm{VD}$ at $40^{\circ} \mathrm{C}(\mathrm{VD} 40), \mathrm{VD}$ at $60^{\circ} \mathrm{C}(\mathrm{VD} 60)$, ID at $40^{\circ} \mathrm{C}$ (ID40), ID at $60^{\circ} \mathrm{C}$ (ID60) samples, while MD had the lowest $\mathrm{L}^{*}$ and the highest $\Delta \mathrm{E}$ values. In fact, during VD process, less oxygen was present in a drying chamber under low pressure. Hence, the principal cause of color darkening of dried P. eryngii could be due to the heating during drying, causing non-enzymatic browning reactions that depended on heating temperature and time. The change in color of MD P. eryngii slices indicated that browning occurred more intensely because of non-enzymatic browning. Similarly, some studies reported that ID shiitake mushroom, carrot and garlic exhibited better color than MD products ${ }^{14,23}$. The above results indicated that FD can better retain the color of dried P. eryngii slices.

Shrinkage ratio. The SR of different dried P. eryngii slices is shown in Fig. 1. VD40, VD60, ID40, ID60 and MD samples had the higher SR ranged from 0.81 to 0.85 , but there was no significant difference. The followings were ND, HD40 and HD60 samples with the SR values ranged from 0.72 to 0.73 . The lowest SR was found in FD products (0.19), indicating that the volume of $P$. eryngii slices remained unchanged during FD process. Drying process accompanied with a complicated mass, heat, and momentum transportation within the food products with multiple phases such as solids, liquid water, and gas ${ }^{24}$. In FD system, an extensive pore network was left by the sublimation of ice, and therefore, little shrinkage took place ${ }^{25}$. Similar to ND, HD was a convective drying process, and the shrinkage was more obvious compared to $\mathrm{FD}^{14}$. VD process in this study took longer time than HD under the same temperature, which made the product shrink and formed hardened crust. In ID process, the infrared radiation penetrated the product, and then converted to thermal energy through molecular vibration, and these heat was finally absorbed by the materials without heating the surrounding air ${ }^{15,26,27}$. For MD sample, the microwave energy created a very porous structure of the mushrooms, facilitating the transport of water vapor $^{24}$, which resulted in cell swelling because water evaporation was accelerated by the preferential absorption 


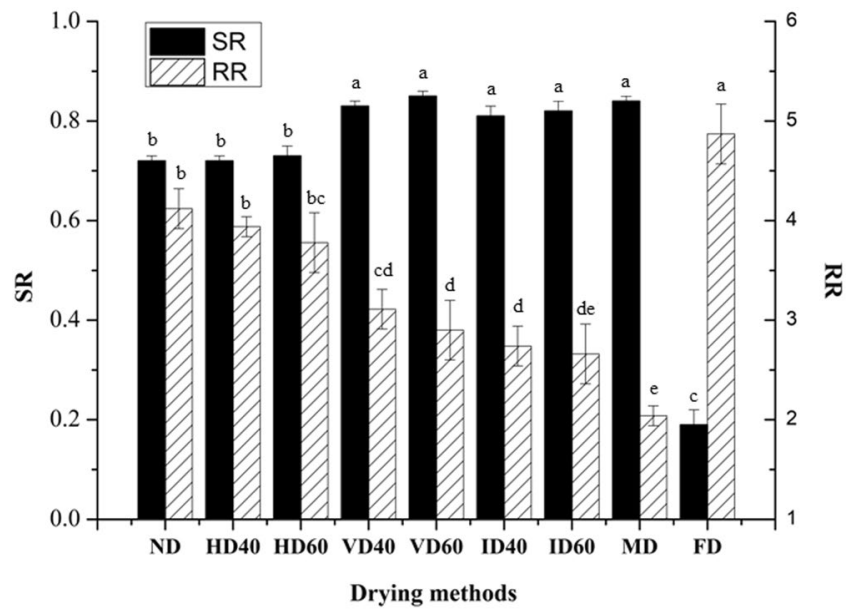

Figure 1. Shrinkage ratio (SR) and rehydration ratio (RR) of dried P. eryngii using different drying methods. Different small letters indicate statistically significant differences between the means $(p<0.05)$ for SR and RR.

of microwave energy. However, negative pressure occurred within the mushrooms, offsetting the puffing process. Hence, the SR of VD, MD and ID samples were the highest. Different results are also reported by other researchers. Baysal et al. reported that SR of MD sample was significantly higher than that of HD and ID samples ${ }^{23}$, while Tian et al. reported that SR of HD sample was significantly higher than that of VD and MD samples ${ }^{9}$. In general, $\mathrm{VD}, \mathrm{ID}$ and MD mushrooms were significantly greater than that of ND and HD mushrooms $(p<0.05)$ in terms of SR, while the lowest SR was found in FD products.

Rehydration ratio. The RR of dried P. eryngii slices treated with different drying methods are given in Fig. 1. FD sample showed the highest RR (4.87), followed by ND, HD40 and HD60 mushrooms, which had no significant difference $(p<0.05)$. The physical and chemical changes during drying process had significant influences on $\mathrm{RR}$, so did the porosity of surface pores and internal structure of the products ${ }^{14}$. The ND, conventional HD and VD resulted in obvious shrinking of mushrooms, forming a dense structure, and maybe just the collapsed capillaries reduce the water retention ability during rehydration ${ }^{14}$. Contrary to the results of SR, the RR of MD sample was the lowest (2.04), followed by VD 60, ID 40 and ID 60 samples. Similar results were reported by some studies $^{14,28}$. In fact, we also found the surface of MD product exhibited serious shrinkage and a hard crust, decreasing the rehydration capacity. There had little effect of drying temperature on rehydration capacity of the P. eryngii slices. However, samples dried by lower temperature had a relatively higher RR than those dried by higher temperature. Similar tendency was also observed in the some studies ${ }^{29,30}$. This may be associated with more intense moisture change of the samples at higher temperature, which caused more seriously damage to the capillaries and further resulted in modifications of osmotic properties of the cell as well as lower diffusion of water through the surface during rehydration ${ }^{31}$. In addition, there was moderate negative correlation $(p<0.05)$ between the RR and SR, and the correlation coefficient was 0.69 (not shown).

Firmness and crispness. The firmness and crispness of $P$. eryngii slices dried with different drying methods are illustrated in Fig. 2. Firmness can be related to the force performed by mastication that took part during eating. The higher the firmness value, the harder it was to chew ${ }^{14}$. The highest firmness was observed for MD sample $\left(6635 \mathrm{~N} \mathrm{~mm}^{-1}\right)$, followed by VD60, VD40, ID60, ID40, HD60, HD40, ND, and FD samples. According to Fig. 2, MD and VD samples exhibited the highest crispness values, followed by ID samples. FD showed the lowest crispness value, followed by ND and HD. Besides, it can be observed that drying temperature had a positive effect on the firmness while no influence on the crispness. These textural variations could be explained by changes in the plant cell wall, which occurred during drying processing with different temperatures and methods, causing significant decrease in internal pressure ${ }^{8,31}$. Furthermore, there was a high positive correlation $(p<0.01)$ between the firmness and the crispness of dried P. eryngii slices, and the correlation coefficient was 0.95 (not shown).

Microstructure. Figure 3 showed scanning electron microscopy (SEM) micrographs of the surface and lateral section of dried P. eryngii slices with different drying methods. The images showed that drying methods had a obvious effect on the tissue structure of $P$. eryngii slices. As expected, the FD samples showed the most plenty of pores in the surface and uniform honeycomb networks in the interior, which almost had no collapsed structure. This phenomenon can be explained by the fact thatthe original dimensions of the product were maintained first by freezing during FD process, then the ice was sublimed under a high vacuum, and thus the destruction of FD products cells could be minimized ${ }^{32}$. It also provided a good way for the infiltration of water during rehydration process, and thus the highest RR, the lowest SR. Compared with FD sample, larger but less pores were seen in the surface of HD samples which indicated more cellular tissue collapse and shrinkage. The morphology in the interior of the HD samples was relatively dense, which partly explained the increasing firmness in HD samples. Compared with HD, VD samples had an irregular surface with a few small cavities, while the organizational structure revealed multiple channels and large irregularities. In VD process, the drying process was conducted 


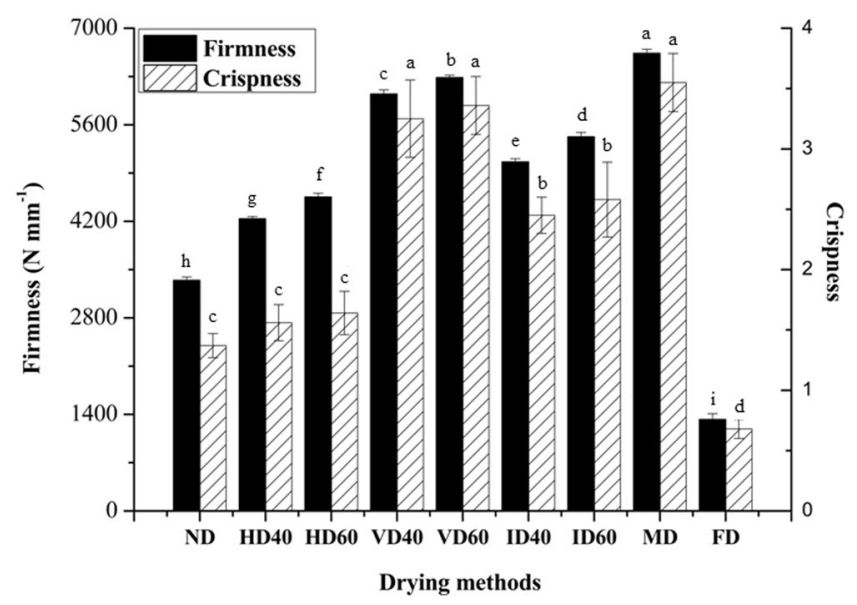

Figure 2. Firmness and crispness of dried P. eryngii using different drying methods. Different small letters indicate statistically significant differences between the means $(p<0.05)$ for firmness and crispness.

under negative vacuum pressure, and thus a reducing boiling point of water made the whole process more rapidly. Finally, a very porous interior structure was formed in the interior of VD samples ${ }^{24}$. A long time high temperature treatment may cause a collapsed structure, a rapid shrinkage and a hard shell, all of which affected the water absorption capacity of the materials ${ }^{33}$. ID samples showed a dense surface layer or crust with few holes but a porous and densest internal structure, which may be due to the limited depth of infrared radiation when penetrating from the surface into the interior. The uneven distribution of water diffusion as well as the collapse of the cellular structure on the surface finally resulted in the uneven structures in ID samples ${ }^{14}$. Different results were reported by Pan et al. who demonstrated that application of ID was better compared to HD for the microstructure of dehydrated banana ${ }^{34}$. The surface of MD samples stacked together and showed almost invisible pores but had a clear porous internal structure. Microwave energy had the ability of selective heating on the interior portions of the products and created a high steam pressure. The dried surface looks like a barrier to hinder the release of the pressure and the product was thus puffed ${ }^{8}$, which also led to a hardening texture and a poor rehydration property. Besides, a lot of soluble viscous polysaccharide substances were transported to the surface when ID and MD were applied to P. eryngii. In consequence, a hard crust would be formed in both ID and MD products, just like roasting, and these samples also got the lowest RR and highest firmness and crispness values.

Nutrient components. The chemical compositions of fresh and dried P. eryngii slices treated with different drying methods are listed in Table 2. The moisture content of fresh P. eryngii was $89.8 \%$ based on fresh weight (fw). Largely consistent with the previous results ${ }^{35}$, other proximate compositions are listed in the following order $(\mathrm{g} / 100 \mathrm{~g}$ dry weight $(\mathrm{dw}))$ : carbohydrate $(63.4 \pm 0.5)>$ protein $(22.1 \pm 0.2)>$ ash $(6.5 \pm 0.2)>$ reducing sugar $(2.9 \pm 0.3)>$ fat $(2.5 \pm 0.2)$. As expected, the final moisture contents of dried P. eryngii using different drying methods ranged from 4.2 to $4.9 \mathrm{~g} / 100 \mathrm{~g}$ dw and showed no significant difference $(\mathrm{p}<0.05)$.

The results revealed that the ash contents, ranging from 6.3 to $6.9 \mathrm{~g} / 100 \mathrm{~g} \mathrm{dw}$, were not affected by drying methods. The protein contents of samples using different drying methods are listed in the following order: $\mathrm{FD}>$ fresh, ND and HD40 > HD60 > VD40, VD60 and ID40 > ID60 > MD. There was no significant difference in fat content among the fresh, FD, ND, HD, and VD samples, while ID and MD showed significant lower fat contents. During ID, the rapid heating of mushrooms by infrared radiation may promote fat oxidation ${ }^{15}$. Unlike ID, heating was generated within the samples in MD, which greatly improved the heating efficiency and also caused fat oxidation. The reducing sugar contents of samples using different drying methods are listed in the following order: fresh, FD, ND and HD40 > HD60, VD40, VD60 and ID40 > ID60 and MD. Contrary to fat content, MD and ID 60 samples got the highest values in carbohydrate contents. The chemical compositions of FD, ND and HD40 samples showed high similarity to fresh P. eryngii.

Free amino acids. The contents of free amino acids (FAA) compositions of fresh and dried P. eryngii slices treated with different drying methods are given in Table 3. Glutamic acid (Glu), alanine (Ala), phenylalanine (Phe) and lysine (Lys) exhibited higher amounts in all P. eryngii samples, which was similar to the previous reports $^{36-38}$. The content of total FAA (TFAA) in fresh sample was $59.06 \mathrm{mg} / \mathrm{g} \mathrm{dw}$, which was much higher than the previous report with $18.07 \mathrm{mg} / \mathrm{g}$ dw of TFAA ${ }^{20}$. The TFAA content decreased significantly $(p<0.05)$ in the dried samples with a descending order as follows: $\mathrm{FD}>\mathrm{ND}>\mathrm{HD} 40>\mathrm{VD} 40>\mathrm{HD} 60>\mathrm{ID} 40>\mathrm{VD} 60>\mathrm{ID} 60>$ MD. It was worth mentioning that the FD product contained more Asp, Phe, Tyr and Ser than the fresh mushroom. During FD process, some free amino acids including Glu, His, and Phe, might be released during proteolysis, and after that, the contents of free amino acids decreased due to the strecker degradation of free amino acids and the Maillard reaction ${ }^{39-42}$. Eight essential amino acids (EAA) for humans were detected in these samples, and the total contents of EAA (TEAA) ranged from 5.03 to $26.31 \mathrm{mg} / \mathrm{g}$. The lowest concentration was observed in MD sample and the highest in fresh sample. The contents of non-essential amino acids (NEAA) of samples had the same trend with EAA and TFAA. The contribution of total free amino acids to the total crude protein was calculated and showed in Table 3. The percentage of TFAA/protein in different samples ordered similar to the 

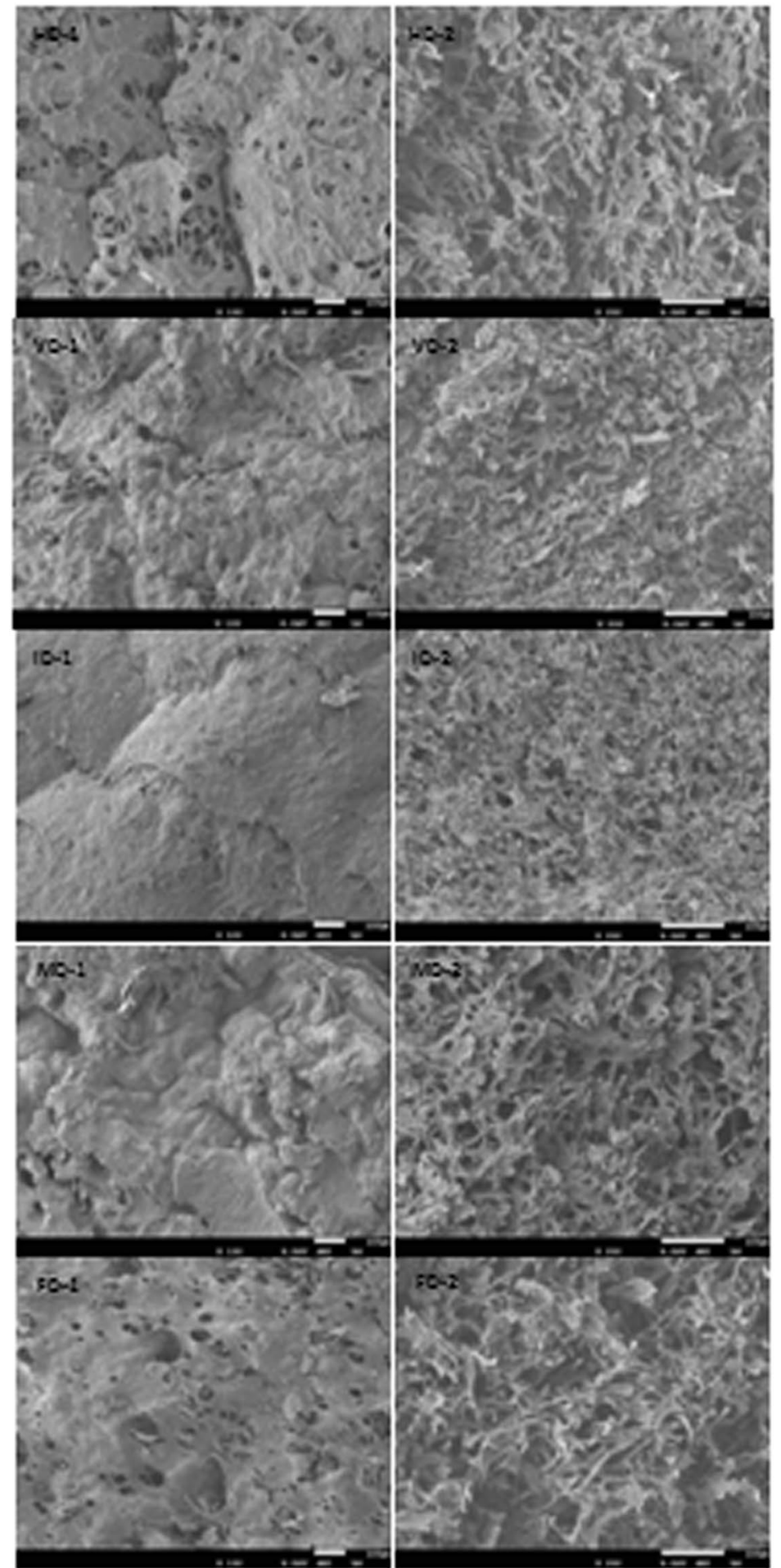

Figure 3. SEM micrographs of dried P. eryngii samples. the left, samples surface; the right, samples lateral section.

content of TFAA. Heating would promote proteolysis as well as non-enzymatic Maillard reactions between amino acids and reducing sugars in mushrooms during the drying process ${ }^{39}$. These results agreed with those for protein content, reducing sugar content and color values, suggesting the amount of FAA released from proteolysis was lower than that of FAA lost in Maillard reaction during ND, HD, VD, ID and MD drying process, and the higher temperature can led to mushrooms darken and hardness ${ }^{12}$.

Differentiation by cluster analysis. In order to establish differences among different drying methods, a cluster analysis is conducted on FAA contents according to squared Euclidean distance methods (Fig. 4). The 


\begin{tabular}{|l|l|l|l|l|l|l|}
\hline & Moisture & Protein & Fat & Ash & $\begin{array}{l}\text { Reducing } \\
\text { sugar }\end{array}$ & Carbohydrate \\
\hline Fresh & & $22.1 \pm 0.2 \mathrm{~b}$ & $2.5 \pm 0.2 \mathrm{a}$ & $6.5 \pm 0.2 \mathrm{a}$ & $2.9 \pm 0.3 \mathrm{a}$ & $63.4 \pm 0.5 \mathrm{e}$ \\
\hline ND & $4.7 \pm 0.4 \mathrm{a}$ & $21.9 \pm 0.1 \mathrm{~b}$ & $2.3 \pm 0.1 \mathrm{a}$ & $6.7 \pm 0.3 \mathrm{a}$ & $2.8 \pm 0.2 \mathrm{a}$ & $63.3 \pm 0.7 \mathrm{e}$ \\
\hline HD40 & $4.6 \pm 0.3 \mathrm{a}$ & $21.4 \pm 0.3 \mathrm{bc}$ & $2.3 \pm 0.3 \mathrm{a}$ & $6.4 \pm 0.1 \mathrm{a}$ & $2.4 \pm 0.1 \mathrm{ab}$ & $64.3 \pm 0.5 \mathrm{e}$ \\
\hline HD60 & $4.5 \pm 0.2 \mathrm{a}$ & $20.8 \pm 0.4 \mathrm{c}$ & $2.4 \pm 0.1 \mathrm{a}$ & $6.3 \pm 0.4 \mathrm{a}$ & $2.0 \pm 0.2 \mathrm{bc}$ & $65.0 \pm 0.6 \mathrm{de}$ \\
\hline VD40 & $4.9 \pm 0.5 \mathrm{a}$ & $18.2 \pm 0.2 \mathrm{~d}$ & $2.3 \pm 0.2 \mathrm{a}$ & $6.5 \pm 0.5 \mathrm{a}$ & $2.0 \pm 0.2 \mathrm{bc}$ & $67.1 \pm 0.4 \mathrm{~cd}$ \\
\hline VD60 & $4.8 \pm 0.3 \mathrm{a}$ & $17.5 \pm 0.5 \mathrm{de}$ & $2.2 \pm 0.4 \mathrm{a}$ & $6.4 \pm 0.6 \mathrm{a}$ & $1.5 \pm 0.1 \mathrm{~cd}$ & $68.1 \pm 0.5 \mathrm{bc}$ \\
\hline ID40 & $4.5 \pm 0.4 \mathrm{a}$ & $17.9 \pm 0.1 \mathrm{de}$ & $1.5 \pm 0.2 \mathrm{~b}$ & $6.6 \pm 0.3 \mathrm{a}$ & $1.9 \pm 0.2 \mathrm{bc}$ & $68.5 \pm 0.6 \mathrm{bc}$ \\
\hline ID60 & $4.4 \pm 0.2 \mathrm{a}$ & $17.1 \pm 0.4 \mathrm{e}$ & $1.4 \pm 0.1 \mathrm{~b}$ & $6.4 \pm 0.2 \mathrm{a}$ & $1.3 \pm 0.1 \mathrm{de}$ & $69.7 \pm 1.3 \mathrm{ab}$ \\
\hline MD & $4.2 \pm 0.4 \mathrm{a}$ & $15.6 \pm 0.3 \mathrm{f}$ & $1.2 \pm 0.3 \mathrm{~b}$ & $6.9 \pm 0.6 \mathrm{a}$ & $0.8 \pm 0.1 \mathrm{e}$ & $71.1 \pm 1.0 \mathrm{a}$ \\
\hline FD & $4.4 \pm 0.6 \mathrm{a}$ & $25.7 \pm 0.2 \mathrm{a}$ & $2.1 \pm 0.2 \mathrm{a}$ & $6.5 \pm 0.4 \mathrm{a}$ & $2.9 \pm 0.3 \mathrm{a}$ & $60.3 \pm 0.8 \mathrm{f}$ \\
\hline
\end{tabular}

Table 2. Moisture content and proximate compositions ( $\mathrm{g} / 100 \mathrm{~g} \mathrm{dw}$ ) of fresh and dried P. eryngii samples. Values are expressed as mean $\pm \mathrm{SD}$ of triplicate measurements. Different letters within a column indicate statistically significant differences between the means $(\mathrm{p}<0.05)$ for moisture, protein, fat, ash, reducing sugar and carbohydrate.

results showed that all samples were divided in to five different clusters. Cluster 1 included three drying samples (HD40, VD40 and HD60), which was further divided into two sub-clusters (I and II). The TEAA contents of HD40 and VD40 samples in sub-cluster I showed high similarity due to the same temperature, which was the critical factor of Maillard reaction causing the loss of FAA, while HD60 sample in sub-cluster II was different. The TFAA content of VD40 sample was lower than that of HD40, due to the longer drying time in VD process. ID40, ID60 and VD60 products were brought together in cluster 2. With the Euclidean distance increasing, cluster 1 and 2 got together, which meant that there was a similarity between two clusters. Cluster 3 was grouped with others, which appeared the sample dried by MD with low similarity with others. Fresh sample in cluster 4 exhibited the highest TFAA and high similarity to FD sample, which meant FD process was the most effective drying method to preserve the FAA of $P$. eryngii. The cluster 5 contained only ND sample. Besides, as the Euclidean distance increased, clusters 4 and 5 got together, which meant that ND sample had more similarities with fresh and FD samples than others.

\section{Conclusion}

In conclusion, the physicochemical properties, microstructures, nutritional compositions, and free amino acids of Pleurotus eryngii were significantly affected by different drying methods. Among them, FD was the most effective drying method and retained the main characteristics of the fresh $P$. eryngii in physicochemical properties, microstructures, nutritional compositions and free amino acids, followed by ND and HD40. However, it was worth mentioning that FD equipments was rather expensive, and the processing procedure was time and energy consuming. MD treatment damaged the physicochemical properties of $P$. eryngii slices and resulted in massive losses of the main nutrients and free amino acids. These results will provide a theoretical basis for industrial processing of $P$. eryngii. It is well known that drying must have an influence of on the bioactivity of the substrate. Therefore, the effects of drying methods on bioactive substances including active polysaccharides and phenols and biological activities of $P$. eryngii still need to be further studied. In addition, further studies need to be performed on the drying process to improve the nutritional quality and health-caring quality of $P$. eryngii.

\section{Materials and Methods}

Materials preparation. Fully mature fresh P. eryngii that is called Xingbaogu in China was harvested from Aokun Biological Agriculture Co. Ltd., Shanxi Province, China. Prior to drying, the fresh P. eryngii samples were cut into slices with thickness of $5.0 \pm 0.2 \mathrm{~mm}$, and then were divided into ten portions at random. Among them, one was used for fresh analysis, and other batches were respectively dried with different methods in optimized conditions to get a water content ( $\leq 5 \%$ dry base). The moisture content of fresh P. eryngii was $89.8 \pm 1.7 \%$ (wet basis), which determined with a hot air oven at $105^{\circ} \mathrm{C}$. After cutting, slices were processed immediately.

Drying process. The P. eryngii slices were dried using the following treatments (1) ND was carried out under natural air flow and ambient temperatures $\left(23-30^{\circ} \mathrm{C}\right)$ for 4 days, (2) HD was conducted in a draught drying cabinet (GZX-9246MBE, Yueming Scientific Instrument Ltd., Shanghai, China) at $40^{\circ} \mathrm{C}$ for $13 \mathrm{~h}$ or $60^{\circ} \mathrm{C}$ for $8 \mathrm{~h}$ until constant weight was achieved respectively, (3) VD was realized with a vacuum drier (DZF-6090, Hecheng Instrument Manufacturing Co., Ltd., Shanghai, China), and the samples were dried at $40^{\circ} \mathrm{C}$ for $19 \mathrm{~h}$ or $60^{\circ} \mathrm{C}$ for $12 \mathrm{~h}$ with vacuum of $0.08 \mathrm{MPa}$, (4) ID was performed in a laboratory scale benchtop infrared drier (YHG 600BS, Botai Laboratory Equipment Ltd., Shanghai, China), and the samples were dried at $40^{\circ} \mathrm{C}$ for $14 \mathrm{~h}$ or $60^{\circ} \mathrm{C}$ for $6 \mathrm{~h},(5) \mathrm{MD}$ was done in a microwave oven (WD900Y, Galanz Enterprise Group Co. Ltd., Guangdong, China) at $240 \mathrm{~W}$ for $10 \mathrm{~min},(6) \mathrm{FD}$ was carried out in a freeze drier at $20^{\circ} \mathrm{C}$ and $30 \mathrm{~Pa}$ for $24 \mathrm{~h}$.

Color measurements. The CIE color coordinates ( $\left.\mathrm{L}^{*}, \mathrm{a}^{*}, \mathrm{~b}^{*}\right)$ of fresh and dried P. eryngii slices were determined with a CM-700D colorimeter (Konica Minolta Optics Inc., Japan). The $\Delta \mathrm{E}$ was calculated according to the formula ${ }^{21}$, 


\begin{tabular}{|c|c|c|c|c|c|c|c|c|c|c|}
\hline \multirow[b]{2}{*}{ Amino acids } & \multirow[b]{2}{*}{ Fresh } & \multirow[b]{2}{*}{ ND } & \multirow[b]{2}{*}{ HD40 } & HD60 & VD40 & VD60 & ID40 & \multirow[b]{2}{*}{ ID60 } & \multirow[b]{2}{*}{ MD } & \multirow[b]{2}{*}{ FD } \\
\hline & & & & \multicolumn{4}{|c|}{ Amino acid content $(\mathrm{mg} / \mathrm{g})$} & & & \\
\hline Glycine & $2.12 \pm 0.15$ & $1.71 \pm 0.21$ & $1.33 \pm 0.16$ & $1.07 \pm 0.11$ & $1.75 \pm 0.26$ & $1.32 \pm 0.16$ & $1.44 \pm 0.06$ & $1.23 \pm 0.66$ & $0.14 \pm 0.08$ & $2.05 \pm 0.16$ \\
\hline Alanine & $6.44 \pm 0.36$ & $5.29 \pm 0.32$ & $4.68 \pm 0.53$ & $3.31 \pm 0.23$ & $3.48 \pm 0.52$ & $2.55 \pm 0.21$ & $2.94 \pm 0.35$ & $2.16 \pm 1.38$ & $1.45 \pm 0.20$ & $5.83 \pm 0.34$ \\
\hline Valine & $0.74 \pm 0.11$ & $0.06 \pm 0.01$ & nd & nd & nd & nd & nd & nd & nd & $0.42 \pm 0.33$ \\
\hline Isoleucine & $2.55 \pm 0.24$ & $1.89 \pm 0.61$ & $1.36 \pm 0.08$ & $1.05 \pm 0.15$ & $1.39 \pm 0.14$ & $0.88 \pm 0.09$ & $0.31 \pm 0.04$ & $0.14 \pm 0.03$ & $0.26 \pm 0.14$ & $2.14 \pm 0.21$ \\
\hline Leucine & $4.32 \pm 0.20$ & $3.79 \pm 0.22$ & $4.08 \pm 0.37$ & $4.84 \pm 0.29$ & $3.92 \pm 0.41$ & $3.73 \pm 0.24$ & $3.25 \pm 0.53$ & $2.66 \pm 0.19$ & $1.46 \pm 0.16$ & $4.03 \pm 0.28$ \\
\hline Aspartic acid & $3.30 \pm 0.25$ & $1.52 \pm 0.12$ & $1.55 \pm 0.19$ & $1.38 \pm 0.11$ & $1.47 \pm 0.22$ & $1.15 \pm 0.15$ & $1.22 \pm 0.21$ & $0.95 \pm 0.11$ & $0.34 \pm 0.07$ & $3.55 \pm 0.33$ \\
\hline Glutamic acid & $8.25 \pm 0.54$ & $5.78 \pm 0.33$ & $5.56 \pm 0.41$ & $6.25 \pm 0.38$ & $4.64 \pm 0.21$ & $3.99 \pm 0.30$ & $4.77 \pm 0.35$ & $4.43 \pm 0.38$ & $2.12 \pm 0.15$ & $7.60 \pm 0.58$ \\
\hline Arginine & $1.48 \pm 0.26$ & $0.51 \pm 0.06$ & $0.31 \pm 0.22$ & $0.11 \pm 0.02$ & $0.45 \pm 0.07$ & $0.08 \pm 0.01$ & $0.05 \pm 0.01$ & nd & nd & $1.33 \pm 0.09$ \\
\hline Lysine & $5.33 \pm 0.52$ & $4.94 \pm 0.15$ & $3.12 \pm 0.29$ & $2.08 \pm 0.15$ & $3.43 \pm 0.17$ & $1.04 \pm 0.16$ & $3.54 \pm 0.39$ & $1.24 \pm 0.99$ & $0.75 \pm 0.09$ & $4.24 \pm 0.22$ \\
\hline Histidine & $2.47 \pm 0.35$ & $1.33 \pm 0.07$ & $1.10 \pm 0.07$ & $0.75 \pm 0.04$ & $0.50 \pm 0.06$ & $0.44 \pm 0.05$ & $1.12 \pm 0.31$ & $0.56 \pm 0.36$ & $0.42 \pm 0.05$ & $1.97 \pm 0.21$ \\
\hline Phenylalanine & $4.96 \pm 0.36$ & $4.13 \pm 0.20$ & $4.00 \pm 0.36$ & $3.20 \pm 0.14$ & $4.34 \pm 0.52$ & $4.05 \pm 0.28$ & $3.06 \pm 0.42$ & $2.75 \pm 0.17$ & $1.55 \pm 0.13$ & $5.11 \pm 0.42$ \\
\hline Tyrosine & $2.98 \pm 0.21$ & $2.54 \pm 0.36$ & $2.13 \pm 0.34$ & $1.78 \pm 0.32$ & $2.34 \pm 0.21$ & $1.90 \pm 0.20$ & $1.77 \pm 0.14$ & $1.12 \pm 0.08$ & $0.54 \pm 0.04$ & $3.54 \pm 0.13$ \\
\hline Threonine & $3.32 \pm 0.31$ & $2.82 \pm 0.09$ & $2.22 \pm 0.16$ & $1.45 \pm 0.24$ & $1.56 \pm 0.08$ & $1.13 \pm 0.14$ & $0.34 \pm 0.44$ & $0.88 \pm 0.11$ & $1.02 \pm 0.06$ & $3.21 \pm 0.36$ \\
\hline Serine & $1.93 \pm 0.26$ & $1.75 \pm 0.35$ & $1.15 \pm 0.26$ & $1.82 \pm 0.14$ & $1.06 \pm 0.09$ & $0.48 \pm 0.06$ & $0.78 \pm 0.62$ & $0.55 \pm 0.06$ & $0.83 \pm 0.05$ & $2.22 \pm 0.17$ \\
\hline Tryptophan & $4.35 \pm 0.41$ & $2.90 \pm 0.31$ & $1.70 \pm 0.14$ & $0.96 \pm 0.13$ & $1.54 \pm 0.27$ & nd & nd & nd & nd & $3.54 \pm 0.24$ \\
\hline Cysteine & $0.85 \pm 0.13$ & $0.24 \pm 0.03$ & nd & nd & nd & nd & nd & nd & nd & $0.50 \pm 0.05$ \\
\hline Methionine & $0.74 \pm 0.10$ & $0.58 \pm 0.06$ & $0.15 \pm 0.03$ & nd & $0.06 \pm 0.01$ & nd & nd & nd & nd & $0.64 \pm 0.08$ \\
\hline Proline & $2.93 \pm 0.31$ & $1.82 \pm 0.08$ & $1.46 \pm 0.15$ & $0.69 \pm 0.10$ & $0.94 \pm 0.13$ & $0.14 \pm 0.06$ & $0.07 \pm 0.01$ & $0.08 \pm 0.01$ & nd & $1.88 \pm 0.11$ \\
\hline TEAA & $26.31 \pm 1.62$ & $21.11 \pm 3.55$ & $16.63 \pm 0.13$ & $13.58 \pm 1.56$ & $16.24 \pm 2.30$ & $10.83 \pm 0.89$ & $10.50 \pm 0.69$ & $7.67 \pm 0.64$ & $5.04 \pm 0.48$ & $23.33 \pm 1.36$ \\
\hline NEAA & $32.75 \pm 0.25$ & $22.49 \pm 0.34$ & $19.27 \pm 0.61$ & $17.16 \pm 0.99$ & $16.63 \pm 1.88$ & $12.05 \pm 0.93$ & $14.16 \pm 1.57$ & $11.08 \pm 1.12$ & $5.84 \pm 0.35$ & $30.47 \pm 2.06$ \\
\hline \multirow[t]{3}{*}{ TFAA } & $59.06 \pm 3.23$ & $43.60 \pm 0.28$ & $35.90 \pm 2.78$ & $30.74 \pm 2.33$ & $32.87 \pm 2.06$ & $22.88 \pm 1.57$ & $24.66 \pm 1.98$ & $18.75 \pm 1.38$ & $10.88 \pm 0.92$ & $53.80 \pm 3.27$ \\
\hline & & & & \multicolumn{4}{|c|}{ TFAA/protein $(\%)$} & & & \\
\hline & $26.72 \pm 2.12$ & $19.91 \pm 1.76$ & $16.78 \pm 2.01$ & $14.78 \pm 1.64$ & $18.06 \pm 2.03$ & $13.07 \pm 1.63$ & $13.78 \pm 1.20$ & $10.96 \pm 0.88$ & $6.97 \pm 0.45$ & $20.93 \pm 1.66$ \\
\hline
\end{tabular}

Table 3. Contents of free amino acids of fresh and dried P. eryngii samples. nd, not detected. Values are expressed as mean $\pm \mathrm{SD}$ of triplicate measurements.

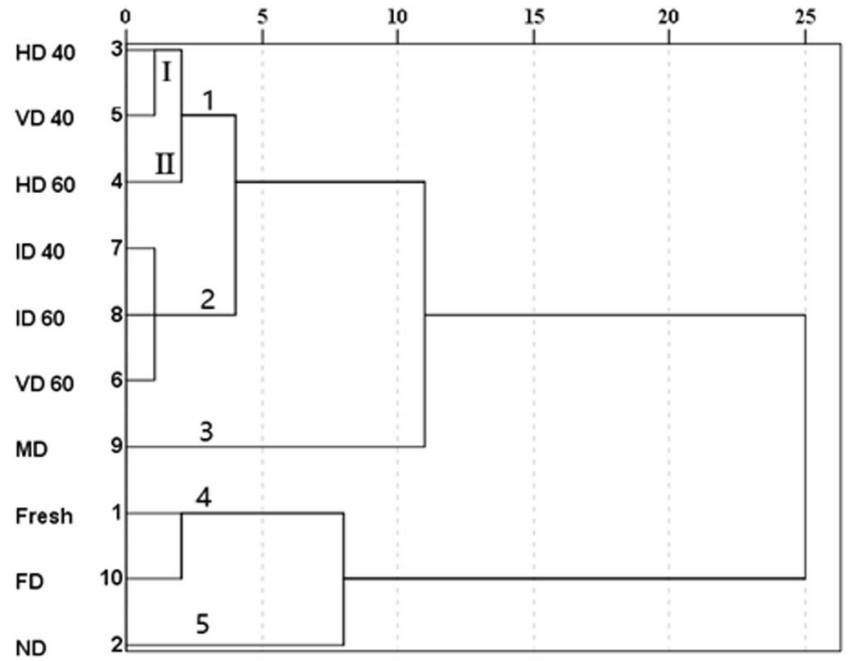

Figure 4. Clustering results of FAA data analysis of fresh and dried P. eryngii using different drying methods.

$$
\Delta E=\sqrt{\left(\mathrm{L}^{*}-\mathrm{L}_{0}\right)^{2}+\left(\mathrm{a}^{*}-\mathrm{a}_{0}\right)^{2}+\left(\mathrm{b}^{*}-\mathrm{b}_{0}\right)^{2}},
$$

where $\mathrm{L}_{0}, \mathrm{a}_{0}$, and $\mathrm{b}_{0}$ referred to the color reading of fresh samples, which was used as control.

Shrinkage ratio. The shrinkage ratio (SR) was measured by a displacement method ${ }^{14}$. The shrinkage ratio of dried P. eryngii slices was calculated according to the formula, $S R=\left(V_{1}-V_{2}\right) / V_{1}$, where $V_{1}$ and $V_{2}$ were the volume $\left(\mathrm{cm}^{3}\right)$ of the fresh and dried samples, respectively.

Rehydration ratio. The rehydration ratio (RR) was determined according to the reported method ${ }^{43}$. Dried slices were weighed $\left(\mathrm{W}_{0}\right)$ and immersed for $30 \mathrm{~min}$ in distilled water at room temperature. Then the rehydrated 
samples were removed, and the slices were weighed again $\left(\mathrm{W}_{1}\right)$. The $\mathrm{RR}$ was calculated according to the formula, $\mathrm{RR}=\left(\mathrm{W}_{1}-\mathrm{W}_{0}\right) / \mathrm{W}_{0}$.

Firmness and crispness. Firmness and crispness of dried P. eryngii slices were evaluated by means of a puncture test carried out by a Texture Analyzer. The probe used was cylindrical with a puncture diameter of $10 \mathrm{~mm}$ and the parameters were preset as follows: test speed $1.0 \mathrm{~mm} \mathrm{~s}^{-1}$, pretest speed $3.0 \mathrm{~mm} \mathrm{~s}^{-1}$, posttest speed $3.0 \mathrm{~mm} \mathrm{~s}^{-1}$, travel distance of $3.0 \mathrm{~mm}$. Firmness $\left(\mathrm{N} \mathrm{mm}^{-1}\right)$ of samples was defined as the maximum force applied to puncture the mushroom. The crispness was defined as the coordinate of the first peak pressure.

Microstructure analysis. The surface morphology and internal structure of dried P. eryngii were observed by scanning electron microscopy (Model JSM-5310LV; JEOL Ltd., Tokyo, Japan) at an accelerating voltage of $6.0 \mathrm{kV}$. The SEM micrographs of the surface and interior of samples were obtained at $100 \times$ magnification and $200 \times$ magnification respectively.

Nutrient components analysis. Ash, protein and fat were determined following the AOAC procedures ${ }^{44}$. The nitrogen factor used for crude protein calculation was $4.38^{13}$. Fat percentage was determined using a Soxhlet apparatus. The content of reducing sugar was estimated by the 3,5-dinitrosalicylic acid spectrophotometric $\operatorname{method}^{10,16}$.

Free amino acids analysis. Free amino acid extraction and analysis were carried out according to the method reported by Li et al. ${ }^{16}$. The $0.2 \mathrm{~g}$ powder samples were added to $20 \mathrm{~mL} 75 \%$ ethanol and shaken with a laboratory rotary shaker at $150 \mathrm{rpm}$ for $30 \mathrm{~min}$ at $70^{\circ} \mathrm{C}$. After centrifugation at $10000 \mathrm{~g}$ and $4{ }^{\circ} \mathrm{C}$ for $15 \mathrm{~min}$, the supernatant was collected, evaporated to dryness. The residual was reconstituted with pH 2.2, $0.2 \mathrm{M}$ sodium citrate loading buffer solution to a final volume of $10 \mathrm{~mL}$. The standard solution and prepared filtrate were analyzed by a automatic amino-acid analyzer (Biochrom Ltd., England). The injection volume and the duration of single run were $20 \mu \mathrm{L}$ and $60 \mathrm{~min}$, respectively. The amino acids were identified and quantified by comparing peak profiles of the mushroom samples with standard amino acid profiles.

Statistical analysis. All experiments were carried out in triplicate and the data were expressed as mean \pm standard deviation (SD). Correlation coefficient, One-way analysis of variance (ANOVA) and Duncan's multiple range test were carried out to determine significant differences $(p<0.05)$ between the means.

Received: 11 September 2019; Accepted: 18 December 2019;

Published online: 10 January 2020

\section{References}

1. Kim, M. Y. et al. Comparison of free amino acid, carbohydrates concentrations in Korean edible and medicinal mushrooms. Food Chem. 113, 386-393 (2009).

2. Sun, Y., Hu, X. \& Li, W. Antioxidant, antitumor and immunostimulatory activities of the polypeptide from Pleurotus eryngii mycelium. Int. J. Biol. Macromol. 97, 323-330 (2017).

3. Vamanu, E., Gatea, F. \& Sârbu, I. In vitro ecological response of the human gut microbiome to bioactive extracts from edible wild mushrooms. Molecules. 23, 2128, https://doi.org/10.3390/molecules23092128 (2018).

4. Kirbag, S. \& Akyuz, M. Effect of various agro-residues on growing periods, yield and biological efficiency of Pleurotus eryngii. J. Food Agric. Environ. 66, 402-405 (2008).

5. Im, C. H. et al. Construction of a genetic linkage map and analysis of quantitative trait loci associated with the agronomically important traits of Pleurotus eryngii. Fungal Genet. Biol. 92, 50-64 (2016).

6. Amodio, M. L., Colelli, G., De Cillis, F. M., Lovino, R. \& Massignan, L. Controlled-atmosphere storage of fresh-cut 'cardoncello' mushrooms (Pleurotus eryngii). Acta Hortic. 599, 731-735 (2003).

7. Akram, K., Ahn, J. J., Yoon, S. R., Kim, G. R. \& Kwon, J. H. Quality attributes of Pleurotus eryngii following gamma irradiation. Postharvest Biol.Tech. 66, 42-47 (2012).

8. Argyropoulos, D., Heindl, A. \& Müller, J. Assessment of convection, hot-air combined with microwave-vacuum and freeze-drying methods for mushrooms with regard to product quality. Int. J. Food Sci. Tech. 46, 333-342 (2011).

9. Tian, Y., Zhao, Y., Huang, J., Zeng, H. \& Zheng, B. Effects of different drying methods on the product quality and volatile compounds of whole shiitake mushrooms. Food Chem. 197, 714-722 (2016).

10. Liu, Y., Zheng, W., Ibrahim, S. A., Yang, H. \& Huang, W. Chemical properties of vacuum-fried Pleurotus eryngii during storage and characterization of brown pigment. Int. J. Food Prop. 20(S3), S2349-S2358 (2018).

11. Boin, E. A. S. F., Azevedo, C. M. A. M., Nunes, J. M. S. A. \& Guerra, M. M. Consumer acceptability and descriptive characterization of fresh and dried king oyster (Pleurotus eryngii) and hedgehog (Hydnum repandum) mushrooms. J. Food Res. 5, 55-64 (2016).

12. Walde, S. G., Velu, V., Jyothirmayi, T. \& Math, R. G. Effects of pretreatments and drying methods on dehydration of mushroom. J. Food Eng. 74, 108-115 (2006).

13. Fernandes, Â. et al. Effects of different processing technologies on chemical and antioxidant parameters of Macrolepiota procera wild mushroom. LWT-Food Sci. Technol. 54, 493-499 (2013).

14. Wang, H., Zhang, M. \& Mujumdar, A. S. Comparison of three new drying methods for drying characteristics and quality of shiitake mushroom (Lentinus edodes). Drying Technol. 32, 1791-1802 (2014).

15. Wang, H. C., Zhang, M. \& Adhikari, B. Drying of shiitake mushroom by combining freeze-drying and mid-infrared radiation. Food Bioprod. Process. 94, 507-517 (2015).

16. Li, W. Q., Hu, Q. P. \& Xu, J. G. Changes in physicochemical characteristics and free amino acids of hawthorn (Crataegus pinnatifida) fruits during maturation. Food Chem. 175, 50-56 (2015).

17. Ucar, T. M. \& Karadag, A. The effects of vacuum and freeze-drying on the physicochemical properties and in vitro digestibility of phenolics in oyster mushroom (Pleurotus ostreatus). J. Food Meas Charact. 1-12, https://doi.org/10.1007/s11694-019-00149-w (2019).

18. Chen, J., Lin, H., Lin, Y., Li, H. \& Wang, Z. Optimized technology of Pleurotus eryngii by microwave-vacuum drying based on quality and energy consumption. Transactions of the Chinese Society of Agricultural Engineering 30(3), 277-284 (2014).

19. Su, D., Lv, W., Wang, Y., Li, D. \& Wang, L. Drying characteristics and water dynamics during microwave hot-air flow rolling drying of Pleurotus eryngii. Drying Technol. 1-12, https://doi.org/10.1080/07373937.2019.1648291 (2019). 
20. Li, X. et al. Effects of drying methods on the tasty compounds of Pleurotus eryngii. Food Chem. 166, 358-364 (2015).

21. Kantrong, H., Tansakul, A. \& Mittal, G. S. Drying characteristics and quality of shiitake mushroom undergoing microwave-vacuum drying and microwave- vacuum combined with infrared drying. J. Food Sci. Tech. 51, 3594-3608 (2014).

22. Xu, J. G. \& Duan, J. L. Effects of drying methods on physico-chemical properties and antioxidant activity of shiitake mushrooms (Lentinus Edodes). Agri. Food Sci. Res. 2, 51-55 (2015).

23. Baysal, T., Icier, F., Ersus, S. \& Ylldı, H. Effects of microwave and infrared drying on the quality of carrot and garlic. European Food Res. Technol. 218, 68-73 (2003).

24. Zhang, M., Tang, J., Mujumdar, A. S. \& Wang, S. Trends in microwave-related drying of fruits and vegetables. Trends Food Sci. Tech. 17, 524-534 (2006)

25. Sosa, N., Salvatori, D. M. \& Schebor, C. Physico-chemical and mechanical properties of apple disks subjected to osmotic dehydration and different drying methods. Food Bioprocess Tech. 5, 1790-1802 (2012).

26. Mongpraneet, S., Abe, T. \& Tsurusaki, T. Accelerated drying of welsh onion by far infrared radiation under vacuum conditions. J. Food Eng. 55, 147-156 (2002).

27. Krishnamurthy, K., Khurana, H. K., Soojin, J., Irudayaraj, J. \& Demirci, A. Infrared heating in food processing: An overview. Compr. Rev. Food Sci. F. 7, 2-13 (2010).

28. Wang, J. \& Sheng, K. C. Far-infrared and microwave drying of peach. LWT-Food Sci. Technol. 39, 247-255 (2006).

29. Wu, L., Orikasa, T., Ogawa, Y. \& Tagawa, A. Vacuum drying characteristics of eggplants. J. Food Eng. 83, 422-429 (2007).

30. Artnaseaw, A., Theerakulpisut, S. \& Benjapiyaporn, C. Drying characteristics of shiitake mushroom and Jinda chili during vacuum heat pump drying. Food Bioprod. Process. 88, 105-114 (2010).

31. Vega-Gálvez, A. et al. Effect of air-drying temperature on physico-chemical properties, antioxidant capacity, colour and total phenolic content of red pepper (Capsicum annuum, L. var. Hungarian). Food Chem. 117, 647-653 (2009).

32. Arumuganathan, T., Manikantan, M. R., Indurani, C., Rai, R. D. \& Kamal, S. Texture and quality parameters of oyster mushroom as influenced by drying methods. Int. Agrophys. 24, 339-342 (2010).

33. Di, W. U. et al. Effects of drying methods on flavor components of Lentinus edodes and Pleurotus eryngii. Science \& Technology of Food Industry 34, 188-191 (in Chinese) (2013).

34. Pan, Z., Shih, C., Mchugh, T. H. \& Hirschberg, E. Study of banana dehydration using sequential infrared radiation heating and freeze-drying. LWT-Food Sci. Technol. 41, 1944-1951 (2008).

35. Cui, F. et al. Changes in chemical components and cytotoxicity at different maturity stages of Pleurotus eryngii fruiting body. J. Agr. Food Chem. 62, 12631-12640 (2014).

36. Li, W. et al. Non-volatile taste components of several cultivated mushrooms. Food Chem. 143, 427-431 (2014).

37. Park, H. S. et al. Nutritional contents and physiological activity of Pleurotus eryngii by extraction solvents. J. Mushroom. 13, 282-287 (2015).

38. Naknaen, P., Itthisoponkul, T. \& Charoenthaikij, P. Proximate compositions, nonvolatile taste components and antioxidant capacities of some dried edible mushrooms collected from Thailand. J. Food Meas. Charact. 9, 259-268 (2015).

39. Yoneda, C., Okubo, K., Kasai, M. \& Hatae, K. Extractive components of boiled-dried scallop adductor muscle and effect on the taste of soup after mixing with chicken leg meat. J. Sci.Food Agr. 85, 809-816 (2005).

40. Li, Q. et al. Effect of different cooking methods on the flavour constituents of mushroom (Agaricus bisporus (Lange) Sing) soup. Int. J. Food Sci. Tech. 46, 1100-1108 (2011).

41. Pei, F. et al. Changes in non-volatile taste components of button mushroom (Agaricus bisporus) during different stages of freeze drying and freeze drying combined with microwave vacuum drying. Food Chem. 165, 547-554 (2014).

42. Kebede, B. T. et al. Effect of high pressure high temperature processing on the volatile fraction of differently coloured carrots. Food Chem. 153, 340-352 (2014).

43. Santossánchez, N. F., Valadezblanco, R., Gómezgómez, M. S., Pérezherrera, A. \& Salascoronado, R. Effect of rotating tray drying on antioxidant components, color and rehydration ratio of tomato saladette slices. LWT-Food Sci.Technol. 46, 298-304 (2012).

44. AOAC. Official methods of analysis (16th ed.). Arlington VA, USA: Association of Official Analytical Chemists (1995).

\section{Acknowledgements}

This work was supported the Natural Science Foundation of Shanxi Province, China (Grant No. 201601D011070).

\section{Author contributions}

Q.P.H. contributed to the design, planning and coordination of the project; R.L.Y. and Q.L. carried out the experiments and conducted the data analysis; R.L.Y. and Q.P.H. wrote and edited the manuscript. All authors participated in discussion about the results and the manuscript.

\section{Competing interests}

The authors declare no competing interests.

\section{Additional information}

Correspondence and requests for materials should be addressed to Q.-P.H.

Reprints and permissions information is available at www.nature.com/reprints.

Publisher's note Springer Nature remains neutral with regard to jurisdictional claims in published maps and institutional affiliations.

(c) (i) Open Access This article is licensed under a Creative Commons Attribution 4.0 International License, which permits use, sharing, adaptation, distribution and reproduction in any medium or format, as long as you give appropriate credit to the original author(s) and the source, provide a link to the Creative Commons license, and indicate if changes were made. The images or other third party material in this article are included in the article's Creative Commons license, unless indicated otherwise in a credit line to the material. If material is not included in the article's Creative Commons license and your intended use is not permitted by statutory regulation or exceeds the permitted use, you will need to obtain permission directly from the copyright holder. To view a copy of this license, visit http://creativecommons.org/licenses/by/4.0/.

(C) The Author(s) 2020 